\title{
The Benefits of High Relaxivity for Brain Tumor Imaging: Results of a Multicenter Intraindividual Crossover Comparison of Gadobenate Dimeglumine with Gadoterate Meglumine (The BENEFIT Study)
}

\author{
(D) M. Vaneckova, (DM. Herman, (DM.P. Smith, (D). Mechl, (D) K.R. Maravilla, (D). Weichet, (D) M.V. Spampinato, (D). Žižka, \\ (D)F.J. Wippold II, (D).J. Baima, (D)R. Babbel, (DE. Bültmann, (DR.Y. Huang, (D).-H. Buhk, A. Bonafé, C. Colosimo, S. Lui, (D) M.A. Kirchin,
} N. Shen, G. Pirovano, and A. Spinazzi

\begin{abstract}
BACKGROUND AND PURPOSE: Gadobenate dimeglumine (MultiHance) has higher rl relaxivity than gadoterate meglumine (Dotarem) which may permit the use of lower doses for MR imaging applications. Our aim was to compare 0.1- and 0.05-mmol/kg body weight gadobenate with $0.1-\mathrm{mmol} / \mathrm{kg}$ body weight gadoterate for MR imaging assessment of brain tumors.
\end{abstract}

MATERIALS AND METHODS: We performed crossover, intraindividual comparison of $0.1-\mathrm{mmol} / \mathrm{kg}$ gadobenate with $0.1-\mathrm{mmol} / \mathrm{kg}$ gadoterate (Arm 1) and 0.05-mmol/kg gadobenate with 0.1-mmol/kg gadoterate (Arm 2). Adult patients with suspected or known brain tumors were randomized to Arm 1 (70 patients) or Arm 2 (107 patients) and underwent 2 identical examinations at 1.5T. The agents were injected in randomized-sequence order, and the 2 examinations were separated by 2-14 days. MR imaging scanners, imaging sequences (T1-weighted spin-echo and T1-weighted high-resolution gradient-echo), and acquisition timing were identical for the 2 examinations. Three blinded readers evaluated images for diagnostic information (degree of definition of lesion extent, lesion border delineation, visualization of lesion internal morphology, contrast enhancement) and quantitatively for percentage lesion enhancement and lesion-to-background ratio. Safety assessments were performed.

RESULTS: In Arm 1, a highly significant superiority $(P<.002)$ of $0.1-\mathrm{mmol} / \mathrm{kg}$ gadobenate was demonstrated by all readers for all end points. In Arm 2, no significant differences $(P>$.1) were observed for any reader and any end point, with the exception of percentage enhancement for reader $2(P<.05)$ in favor of $0.05-\mathrm{mmol} / \mathrm{kg}$ gadobenate. Study agent-related adverse events were reported by $2 / 169(1.2 \%)$ patients after gadobenate and by $5 / 175$ (2.9\%) patients after gadoterate.

CONCLUSIONS: Significantly superior morphologic information and contrast enhancement are demonstrated on brain MR imaging with $0.1-\mathrm{mmol} / \mathrm{kg}$ gadobenate compared with $0.1-\mathrm{mmol} / \mathrm{kg}$ gadoterate. No meaningful differences were recorded between $0.05-\mathrm{mmol} / \mathrm{kg}$ gadobenate and 0.1-mmol/kg gadoterate.

ABBREVIATIONS: GBCA = gadolinium-based contrast agent; $\mathrm{LBR}=$ lesion-to-background ratio; $\mathrm{SI}=$ signal intensity; T1GRE = T1-weighted high resolution gradient-echo; TISE $=$ T1-weighted spin-echo

A

series of large-scale, multicenter, intraindividual, crossover studies have shown that gadobenate dimeglumine (Multi-
Hance; Bracco Diagnostics, Princeton, New Jersey) is superior to gadopentetate dimeglumine (Magnevist; Bayer HealthCare, Wayne, New Jersey), ${ }^{1,2}$ gadodiamide (Omniscan; GE Healthcare, Princeton, New Jersey), ${ }^{3}$ and gadobutrol (Gadavist; Bayer HealthCare $)^{4}$ for enhanced MR imaging of central nervous system tumors when administered at an equivalent approved dose of $0.1 \mathrm{mmol} / \mathrm{kg}$ body weight. The superior imaging performance (ie, significantly greater lesion enhancement and diagnostic informa-

University (S.L.), Chengdu, Sichuan, China; Global Medical \& Regulatory Affairs (M.A.K.), Bracco Imaging S.p.A., Milan, Italy; and Global Medical \& Regulatory Affairs (N.S., G.P., A.S.), Bracco Diagnostics, Monroe, New Jersey.

Please address correspondence to Manuela Vaneckova, MD, Charles University in Prague, First Faculty of Medicine and General University Hospital, Kateřinská 30, CZ-12808 Prague 2, Czech Republic; e-mail: man.van@post.cz

\footnotetext{
- Indicates open access to non-subscribers at www.ajnr.org

Evidence-Based Medicine Level 1.

http://dx.doi.org/10.3174/ajnr.A4468
} 
tion) can be ascribed to the higher $\mathrm{r} 1$ relaxivity of gadobenate in vivo, ${ }^{5}$ which translates into greater signal-intensity (SI) enhancement on T1-weighted images. An early study in 23 patients suggested that $0.1-\mathrm{mmol} / \mathrm{kg}$ gadobenate may provide superior contrast enhancement compared with $0.1-\mathrm{mmol} / \mathrm{kg}$ gadoterate meglumine (Dotarem; Guerbet, Aulnay-sous-Bois, France), another gadolinium-based contrast agent (GBCA) with lower $\mathrm{r} 1 \mathrm{re-}$ laxivity. ${ }^{6}$ However, the sample size was too small to draw firm conclusions. Another more recent study has demonstrated superiority in the quality of visualization of brain lesions for a threequarter $(0.075-\mathrm{mmol} / \mathrm{kg})$ dose of gadobenate over a full 0.1 $\mathrm{mmol} / \mathrm{kg}$ dose of gadoterate in patients undergoing cranial MR imaging. ${ }^{7}$ These results suggest that better or similar SI enhancement and similar imaging performance may be achieved with a reduced gadobenate dose.

The purpose of this multicenter, multinational study in 177 patients referred for morphologic brain MR imaging was first to confirm previous findings ${ }^{6}$ in demonstrating imaging superiority for $0.1-\mathrm{mmol} / \mathrm{kg}$ gadobenate over $0.1-\mathrm{mmol} / \mathrm{kg}$ gadoterate in a properly sized and powered clinical study; and second, to ascertain whether half-dose $(0.05-\mathrm{mmol} / \mathrm{kg})$ gadobenate provides similar diagnostic information to full-dose $(0.1-\mathrm{mmol} / \mathrm{kg})$ gadoterate when these agents are administered in 2 otherwise identical MR imaging examinations at $1.5 \mathrm{~T}$ using a rigorous, double-blind, randomized, intraindividual, crossover study design.

\section{MATERIALS AND METHODS}

The study was compliant with the Health Insurance Portability and Accountability Act, was conducted according to Good Clinical Practice standards, and was registered at www.clinicaltrials. gov (NCT02070380). Ethics committee approval was obtained from all investigating centers, and all patients signed an approved informed consent form before enrollment.

\section{Patients}

One hundred seventy-seven patients referred for contrast-enhanced MR imaging for known or suspected brain tumors were prospectively enrolled in a consecutive manner at 14 participating centers between February 2014 and February 2015 and underwent at least 1 contrast-enhanced MR imaging examination. Two centers enrolled 30 patients each, while a further 8 centers enrolled between 7 and 26 patients. The remaining 4 centers enrolled between 1 and 4 patients. Patients were ineligible if they received any investigational drug within 30 days before study agent administration. Subjects were also excluded if they were to receive any treatment between the 2 examinations that could affect lesion visualization (eg, radiation therapy, steroids, or chemotherapy). Patients were also ineligible if they were pregnant or nursing or had impaired renal function, congestive heart failure, claustrophobia, history of reaction to prior gadolinium contrast agent administration, a cardiac pacemaker, or other contraindications to MR imaging.

The 177 enrolled patients were prospectively randomized to 1 of 2 study arms by means of a central computer-generated randomization code list that was provided to each site before patient enrollment for the assignment of a study arm and an investigational product. To maintain the study blind, a drug-dispensing person was selected at each site for the duration of the study. The drug-dispensing person was responsible for dispensing the 2 investigational products to the appropriate personnel, according to the randomization list. Arm 1 saw 70 patients ( 29 men, 41 women; mean age, $55.3 \pm 15.2$ years; range, $19-86$ years) randomized to receive equivalent $0.1-\mathrm{mmol} / \mathrm{kg}$ doses of gadobenate and gadoterate in 2 otherwise identical examinations, while in Arm 2, 107 patients ( 55 men, 52 women; mean age, $58.3 \pm 13.1$ years; range, 26-86 years) received randomized doses of 0.05 $\mathrm{mmol} / \mathrm{kg}$ gadobenate and $0.1-\mathrm{mmol} / \mathrm{kg}$ gadoterate. Gadobenate was administered first to 31 and 53 patients (Arms 1 and 2, respectively), while gadoterate was administered first to 39 and 54 patients, respectively.

\section{MR Imaging}

MR imaging was performed on $1.5 \mathrm{~T}$ systems from several vendors (Avanto/Aera, $n=67$; Siemens, Erlangen, Germany; Achieva/ Intera, $n=66$; Philips Healthcare, Best, the Netherlands; HDxt/ Excite, $n=44$; GE Healthcare, Milwaukee, Wisconsin) by using a multichannel head coil. Despite the benefits of 3T systems, particularly for advanced imaging techniques, $1.5 \mathrm{~T}$ systems were used in this study because they are still more commonly used throughout the United States, Europe, and other areas worldwide.

A rigorously controlled imaging protocol comprising $\mathrm{T} 1$ weighted spin-echo (T1SE), T2-weighted fast spin-echo , and T2weighted FLAIR acquisitions before contrast injection and T1SE and 3D T1-weighted high-resolution gradient-echo (T1GRE) acquisitions after injection ensured protocol uniformity across sites and within individual patients. Sequence parameters varied within predefined ranges necessitated by the use of different imaging systems. However, the same MR imaging scanner, imaging planes, section prescriptions, and sequence parameters were used for both examinations in each patient. Scan parameters were as follows: for the T1SE sequence: $\mathrm{TR}=400-707 \mathrm{~ms}$, TE $=8-15$ $\mathrm{ms}$, excitations $=1-2$, section thickness $=4-5 \mathrm{~mm}, \mathrm{FOV}=22 \times$ $17-24 \times 24 \mathrm{~cm}$; for the T1GRE sequence: TR $=6-2200 \mathrm{~ms}$, TE $=$ 2-5 ms, flip angle $=8^{\circ}-30^{\circ}$, excitations $=0.8-1$, section thickness $=1-3 \mathrm{~mm}, \mathrm{FOV}=23 \times 18-29 \times 29 \mathrm{~cm}$. Parallel imaging was not used for any patient. Axial scans were all acquired along the inferior callosal plane to ensure image comparability between scans within patient comparisons and across patients.

IV contrast agent administration to patients in Arm 1 was performed identically for both examinations at $0.1 \mathrm{mmol} / \mathrm{kg}$ of body weight $(0.2 \mathrm{~mL} / \mathrm{kg}$ for both agents) by using either manual bolus injection $(n=57)$ or a power injector $(n=13)$. Contrast administration to patients in Arm 2 was performed at 0.1 $\mathrm{mmol} / \mathrm{kg}$ for gadoterate but at $0.05 \mathrm{mmol} / \mathrm{kg}(0.1 \mathrm{~mL} / \mathrm{kg})$ for gadobenate, again by manual bolus injection $(n=83)$ or a power injector $(n=24)$. All injections were followed by a saline flush of up to $30 \mathrm{~mL}$. To maintain the study blind, an independent drugdispensing person administered each agent in the order determined by the randomization list.

Postcontrast image acquisition began at a prespecified time between 3 and 10 minutes after injection but could vary within this range depending on the site-specific protocol. However, the timing and order of postcontrast sequences were mandated to be identical for both examinations within each patient. The interval 
between MR imaging examinations was $>48$ hours to avoid carryover effects but $<14$ days to minimize the chance of disease progression.

\section{Image Evaluation}

All images were evaluated by 3 independent neuroradiologists (A.B., C.C., S.L.; 34, 35, and 7 years of neuroradiology experience, respectively) who were unaffiliated with the study centers and blinded to the contrast agent used, patient clinical and radiologic information, and interpretations by on-site investigators. Each reader evaluated all patient images independently on a multimonitor workstation (AquariusNET Server, Version 4.4.1.4; TeraRecon, San Mateo, California) in terms of qualitative and quantitative end points.

Qualitative and quantitative assessment of images from each patient in each study arm was performed with images presented in global matched-pairs fashion. For each randomized patient number, all images from examination 1 were displayed simultaneously with the images from examination 2. Each reader could perform all routine interactive image manipulation functions (ie, window/ level, zoom, pan) on both image sets. If the postinjection images from either examination were considered technically inadequate by any of the 3 readers (eg, if artifacts compromised interpretability), no further assessment was performed for that patient by that reader. Once the readers' assessments were recorded and signed on an electronic case report form, the data base for that reading was automatically locked.

\section{Qualitative Assessment}

Technically adequate images were evaluated qualitatively for diagnostic information and scored in terms of overall diagnostic preference and quality of the following: 1) lesion border delineation, 2) definition of extent of disease, 3) visualization of lesion internal morphology, and 4) lesion contrast enhancement compared with surrounding normal tissue. All assessments were performed by using 3-point scales from -1 (examination 1 better) through 0 (examinations equal) to +1 (examination 2 better). For the various end points, superiority for 1 examination was recorded if it allowed better separation of $\geq 1$ lesion from surrounding tissue, structures, or edema; better definition of lesion extent; clearer depiction of intralesion features; better contrast between lesions and surrounding normal tissue; or the ability to identify $\geq 1$ lesion seen only on that examination.

\section{Quantitative Assessment}

Quantitative evaluation was also performed by each reader, independently, by using a simultaneous matched-pairs approach. SI measurements were made by using ROIs positioned on up to 3 enhancing lesions per patient identified on postcontrast images from both examinations and on areas of normal brain parenchyma in the same section. To ensure that ROIs of equal size (placed to include the largest possible area) were positioned at identical coordinates on all corresponding image sets, each ROI placed on the selected postinjection image from one examination appeared simultaneously on the corresponding image from the other examination. Minor adjustments to the ROI position were permitted to allow for slight differences in patient alignment, al- ways taking care to avoid the inclusion of vessels. When multiple lesions were present, ROIs were placed on up to 3 of the largest, most conspicuous lesions. SI values determined on a pixel-bypixel basis were used to calculate the percentage enhancement (E\%) of lesions and the postcontrast-precontrast lesion-to-background ratio (LBR) on T1SE sequences by using the equations below:

$$
\begin{gathered}
\mathrm{E} \%=\frac{\mathrm{SI} \text { of lesion }(\text { postcontrast })-\mathrm{SI} \text { of lesion (precontrast) }}{\text { SI of lesion (precontrast) }} \times 100, \\
\mathrm{LBR}=\frac{\mathrm{SI} \text { of lesion }}{\text { SI of brain }}
\end{gathered}
$$

\section{Safety Assessments}

Monitoring for adverse events was performed from the time the patient signed the informed consent form until 24 hours after administration of the first study agent and then from the moment the second study agent was administered until 24 hours after administration of the second agent. Events were classified as serious according to the definitions of the US Food and Drug Administration in the Code of Federal Regulation Title 21, Volume 5 Revised, as of April 1, 2014 (http://www.accessdata.fda.gov/scripts/ cdrh/cfdocs/cfcfr/cfrsearch.cfm?fr=312.32). Decisions on event severity and its relationship to the study agent (has reasonable possibility or not) were made by the investigating radiologist.

\section{Statistical Analysis}

Power determination was based on the primary efficacy assumption that gadobenate is superior to gadoterate according to reader preference. Sample sizes were determined (nQuery Advisor, Version 7.0; Statistical Solutions, Cork, Ireland) on the basis of the results of a previous study that had a similar crossover design. ${ }^{3}$ For the full-dose gadobenate arm (Arm 1) assuming an "equal" response in $50 \%$ of cases, a ratio of preference for either agent of $4: 1$, and an effect size of 0.18 , evaluation of 61 subjects was considered necessary to demonstrate the difference in preference with $85 \%$ of power at an $\alpha$ level of .05. Considering a drop-out rate of $15 \%$, enrollment of approximately 72 subjects was needed. For the halfdose gadobenate arm (Arm 2), again assuming an "equal" response in $50 \%$ of cases but with a ratio of preference for either agent of $3: 1$ and an effect size of 0.125 , evaluation of 88 subjects was considered necessary for $85 \%$ of power at an $\alpha$ level of .05. If one assumed a drop-out rate of $15 \%$, enrollment of approximately 104 subjects was needed.

Differences in demographic characteristics between the 2 administration orders within each study arm were tested by using the $t$ test for continuous variables or the Fisher exact test for categoric variables.

Analysis of blinded-reader evaluations was performed by using the statistical software package SAS, Version 9.2 (SAS Institute, Cary, North Carolina). The distribution of reader preferences in diagnostic information end points was tested statistically by using the Wilcoxon signed rank test. Interreader agreement for diagnostic findings was presented as percentage agreement for the 3 readers and assessed by using generalized $\kappa$ statistics. Agreement 
Table 1: Final lesion diagnoses

\begin{tabular}{|c|c|c|}
\hline Lesion Diagnosis & $\begin{array}{c}\text { Arm 1: } 0.1-\mathrm{mmol} / \mathrm{kg} \\
\text { Gadobenate vs } 0.1-\mathrm{mmol} / \mathrm{kg} \\
\text { Gadoterate }(n=63)\end{array}$ & $\begin{array}{c}\text { Arm 2: } 0.05-\mathrm{mmol} / \mathrm{kg} \\
\text { Gadobenate vs } 0.1-\mathrm{mmol} / \mathrm{kg} \\
\text { Gadoterate }(n=96)\end{array}$ \\
\hline Anaplastic astrocytoma & 1 & 1 \\
\hline Pilocytic astrocytoma & - & 2 \\
\hline Low-grade astrocytoma & 3 & 1 \\
\hline Oligoastrocytoma & 1 & 3 \\
\hline High-grade glioma & 1 & 1 \\
\hline Glioblastoma multiforme & 10 & 18 \\
\hline Oligodendroglioma & 2 & - \\
\hline Malignant lymphoma & 1 & 3 \\
\hline Metastatic tumors, total & 26 & 47 \\
\hline Lung & 13 & 23 \\
\hline Breast & 6 & 4 \\
\hline Melanoma & 4 & 2 \\
\hline Ovarian & - & 2 \\
\hline Kidney & 1 & 3 \\
\hline Other & 1 & 7 \\
\hline Unknown & 1 & 6 \\
\hline Tumor (unknown origin) & - & 3 \\
\hline Ependymoma & 2 & - \\
\hline Meningioma & 11 & 7 \\
\hline Schwannoma & 2 & 1 \\
\hline Hemangioblastoma & 1 & 5 \\
\hline Cystic craniopharyngioma & 1 & 1 \\
\hline Acute disseminate encephalomyelitis & 1 & - \\
\hline Neurofibromatosis & - & 1 \\
\hline Capillary telangiectasia & - & 1 \\
\hline Subdural hematoma & - & 1 \\
\hline
\end{tabular}

$58.2 \pm 13.4$ years; range, $26-86$ years). There were no meaningful betweensequence differences in either study arm for $\operatorname{sex}(P=1.0, P=.841$; Arms 1 and 2, respectively), age $(P=.634, P=.038)$, age group ( $18-64$ years, $\geq 65$ years; $P=$ $.274, P=.283)$, weight $(P=.467, P=$ $.212)$, height $(P=.281 ; P=.333)$, or race $(P=1.0 ; P=.496)$ distribution. The diagnoses of the 159 patients evaluated are presented in Table 1. Intra-axial lesions represented approximately $71 \%$ of all patient diagnoses in Arm 1 and 79\% of patient diagnoses in Arm 2.

\section{Qualitative Image Assessment}

Tables 2 and 3 present the results of the 3 blinded readers for global diagnostic preference, lesion-border delineation, disease extent, internal morphology, and qualitative assessment of contrast enhancement for patients in Arms 1 and 2 , respectively. Highly significant $(P \leq$ .0023) superiority for gadobenate over gadoterate was noted by all readers for all qualitative assessments in patients re-

was classified as excellent $(\kappa>0.8)$, good $(\kappa=0.61-0.8)$, moderate $(\kappa=0.41-0.6)$, fair $(\kappa=0.21-0.4)$, or poor $(\kappa \leq 0.2)$.

Differences between gadobenate and gadoterate in terms of quantitative parameters were analyzed by using a mixed-effects model. The change from predose was the response variable, and factors included in the model were patient, sequence, study agent, and predose score; "patient" nested within "sequence" was the random effect. "Study period" was also included to test for potential carryover effects. The Fisher exact test was used to compare the incidence of adverse events for the 2 agents. All statistical tests were conducted at a significance level of $P<.05$.

\section{RESULTS}

\section{Patients}

All 177 enrolled patients who underwent at least 1 contrast-enhanced MR imaging examination were included in the overall safety population. Seven patients randomized to Arm 1 and 11 patients randomized to Arm 2 were excluded from efficacy evaluations because of protocol violations. These 18 patients included 10 who prematurely discontinued after the first examination (withdrawal of consent $[n=5]$, surgical intervention $[n=2]$, change of hospital $[n=1]$, steroid therapy initiated and CT performed $[n=1]$, and stroke detected on examination $1[n=1]$ ) and 8 who were excluded after undergoing both examinations (began chemotherapy after examination $1[n=1]$, stroke $[n=2]$, differences of $>2$ minutes between injection and postdose acquisition start times $[n=2]$, steroid therapy initiated shortly before examination $1[n=1]$, contrast extravasation $[n=1]$, and higher contrast dose (42\%) administered for examination $2[n=1])$. The final efficacy populations therefore comprised 63 patients in Arm 1 (23 men, 40 women; mean age, $56.2 \pm 14.9$ years; range, 19-86 years) and 96 in Arm 2 (49 men, 47 women; mean age, ceiving $0.1-\mathrm{mmol} / \mathrm{kg}$ doses of both agents (Table 2). Conversely, no significant differences were noted by any reader for any qualitative parameter among patients receiving $0.05-\mathrm{mmol} / \mathrm{kg}$ gadobenate and $0.1-\mathrm{mmol} / \mathrm{kg}$ gadoterate (Table 3 ). Agreement among the 3 blinded readers was high for all assessments in Arm 2, ranging from $63.4 \%$ of patients for global diagnostic preference to $84.9 \%$ of patients for visualization of internal lesion morphology. Slightly lower levels of agreement were noted for assessments in Arm 1. Examples of comparative enhancement between gadobenate and gadoterate are shown in Figs 1 and 2.

\section{Quantitative Evaluation}

Readers 1, 2, and 3 recorded lesion SI measurements relative to normal brain parenchyma for 63, 66, and 54 lesions (Arm 1) and 84, 89, and 78 lesions (Arm 2), respectively, on T1SE images and for 60, 61, and 51 lesions (Arm 1) and 82, 85, and 75 lesions (Arm 2), respectively, on T1GRE images. No lesions below $5 \mathrm{~mm}$ were measured by any of the readers. Analysis of quantitative SI data revealed no carryover effects across readers for any assessment $(P>.05)$. The mean percentage signal enhancement of lesions on T1SE images was significantly $(P \leq .0006)$ higher for gadobenate compared with gadoterate for all 3 readers in patients given 0.1 $\mathrm{mmol} / \mathrm{kg}$ doses of both agents (Arm 1), while no meaningful differences were noted between $0.05-\mathrm{mmol} / \mathrm{kg}$ gadobenate and 0.1 $\mathrm{mmol} / \mathrm{kg}$ gadoterate (Arm 2) (Fig 3A).

Similar results were obtained for determinations of LBR (Fig $3 B)$; all 3 readers reported significantly $(P<.0001)$ higher values for LBR with $0.1-\mathrm{mmol} / \mathrm{kg}$ gadobenate compared with 0.1 $\mathrm{mmol} / \mathrm{kg}$ gadoterate, while no differences were noted between $0.05-\mathrm{mmol} / \mathrm{kg}$ gadobenate and $0.1-\mathrm{mmol} / \mathrm{kg}$ gadoterate. LBR findings on T1GRE images were similar: all 3 readers noted sig- 
Table 2: Qualitative assessment of patients with brain tumors: intraindividual comparison of 0.1-mmol/ $\mathbf{k g}$ gadobenate and 0.1-mmol/ kg gadoterate

\begin{tabular}{|c|c|c|c|c|c|c|}
\hline $\begin{array}{c}\text { Diagnostic Information } \\
\text { End Point }\end{array}$ & Reader & $\begin{array}{l}\text { Gadobenate } \\
\text { Preferred }\end{array}$ & No Difference & $\begin{array}{l}\text { Gadoterate } \\
\text { Preferred }\end{array}$ & $\begin{array}{l}\text { Significance } \\
(P \text { Value })^{\mathrm{b}}\end{array}$ & $\begin{array}{c}\text { 3-Reader Agreement } \\
\kappa \text { Value (\% Agreement) }\end{array}$ \\
\hline \multirow[t]{3}{*}{ Global diagnostic preference } & 1 & $31(49.2 \%)$ & $31(49.2 \%)$ & $1(1.6 \%)$ & $<.0001$ & $0.273(50.8 \%)$ \\
\hline & 2 & $51(82.3 \%)$ & $9(14.5 \%)$ & $2(3.2 \%)$ & $<.0001$ & \\
\hline & 3 & $43(69.4 \%)$ & $17(27.4 \%)$ & $2(3.2 \%)$ & $<.0001$ & \\
\hline \multirow[t]{3}{*}{ Lesion-border delineation } & 1 & $29(46.0 \%)$ & $33(52.4 \%)$ & $1(1.6 \%)$ & $<.0001$ & $0.271(44.3 \%)$ \\
\hline & 2 & $34(54.8 \%)$ & $27(43.5 \%)$ & $1(1.6 \%)$ & $<.0001$ & \\
\hline & 3 & $25(40.3 \%)$ & $35(56.5 \%)$ & $2(3.2 \%)$ & $<.0001$ & \\
\hline \multirow[t]{3}{*}{ Definition of disease extent } & 1 & $15(23.8 \%)$ & $48(76.2 \%)$ & 0 & $<.0001$ & $0.286(57.4 \%)$ \\
\hline & 2 & $18(29.0 \%)$ & $43(69.4 \%)$ & $1(1.6 \%)$ & $<.0001$ & \\
\hline & 3 & $15(24.2 \%)$ & $45(72.6 \%)$ & $2(3.2 \%)$ & .0023 & \\
\hline \multirow[t]{3}{*}{ Visualization of lesion internal morphology } & 1 & $10(15.9 \%)$ & $53(84.2 \%)$ & 0 & .002 & $0.215(54.1 \%)$ \\
\hline & 2 & $14(22.6 \%)$ & $48(77.4 \%)$ & 0 & .0001 & \\
\hline & 3 & $23(37.1 \%)$ & $38(61.3 \%)$ & $1(1.6 \%)$ & $<.0001$ & \\
\hline \multirow[t]{3}{*}{ Lesion contrast enhancement } & 1 & $31(49.2 \%)$ & $31(49.2 \%)$ & $1(1.6 \%)$ & $<.0001$ & $0.249(49.2 \%)$ \\
\hline & 2 & $51(82.3 \%)$ & $9(14.5 \%)$ & $2(3.2 \%)$ & $<.0001$ & \\
\hline & 3 & $43(69.4 \%)$ & $17(27.4 \%)$ & $2(3.2 \%)$ & $<.0001$ & \\
\hline
\end{tabular}

${ }^{a}$ Comparisons based on the number of patients with both postdose TISE images assessed and technically adequate: $n=63$ for reader $1, n=62$ for readers 2 and 3 . Numbers in parentheses, except where noted, represent proportions of patients.

b Wilcoxon signed rank test.

Table 3: Qualitative assessment of patients with brain tumors: intraindividual comparison of $0.05-\mathrm{mmol} / \mathrm{kg}$ gadobenate and $0.1-\mathrm{mmol} /$ kg gadoterate

\begin{tabular}{|c|c|c|c|c|c|c|}
\hline $\begin{array}{c}\text { Diagnostic Information } \\
\text { End Point }\end{array}$ & Reader & $\begin{array}{l}\text { Gadobenate } \\
\text { Preferred }\end{array}$ & No Difference & $\begin{array}{l}\text { Gadoterate } \\
\text { Preferred }\end{array}$ & $\begin{array}{l}\text { Significance } \\
(P \text { Value })^{\mathrm{b}}\end{array}$ & $\begin{array}{l}\text { 3-Reader Agreement } \\
\kappa \text { Value (\% Agreement) }\end{array}$ \\
\hline \multirow[t]{3}{*}{ Global diagnostic preference } & 1 & $14(14.6 \%)$ & 75 (78.1\%) & $7(7.3 \%)$ & .13 & $0.505(63.4 \%)$ \\
\hline & 2 & $18(19.2 \%)$ & $56(59.6 \%)$ & $20(21.3 \%)$ & .75 & \\
\hline & 3 & $15(15.8 \%)$ & $63(66.3 \%)$ & $17(17.9 \%)$ & .73 & \\
\hline \multirow[t]{3}{*}{ Lesion-border delineation } & 1 & $11(11.4 \%)$ & $76(79.2 \%)$ & $9(9.4 \%)$ & .824 & $0.493(71.0 \%)$ \\
\hline & 2 & $12(12.8 \%)$ & 66 (70.2\%) & $16(17.0 \%)$ & .46 & \\
\hline & 3 & $8(8.4 \%)$ & $77(81.1 \%)$ & $10(10.5 \%)$ & .815 & \\
\hline \multirow[t]{3}{*}{ Definition of disease extent } & 1 & $6(6.3 \%)$ & $84(87.5 \%)$ & $6(6.3 \%)$ & 1.00 & $0.443(79.6 \%)$ \\
\hline & 2 & $5(5.3 \%)$ & $83(88.3 \%)$ & $6(6.4 \%)$ & 1.00 & \\
\hline & 3 & $7(7.4 \%)$ & 80 (84.2\%) & $8(8.4 \%)$ & 1.00 & \\
\hline \multirow[t]{3}{*}{ Visualization of lesion internal morphology } & 1 & $4(4.2 \%)$ & $88(91.7 \%)$ & $4(4.2 \%)$ & 1.00 & $0.459(84.9 \%)$ \\
\hline & 2 & $3(3.2 \%)$ & $87(92.6 \%)$ & $4(4.3 \%)$ & 1.00 & \\
\hline & 3 & $5(5.3 \%)$ & $82(86.3 \%)$ & $8(8.4 \%)$ & .581 & \\
\hline \multirow[t]{3}{*}{ Lesion contrast enhancement } & 1 & $10(10.4 \%)$ & $77(80.2 \%)$ & $9(9.4 \%)$ & 1.00 & $0.531(66.7 \%)$ \\
\hline & 2 & $18(19.2 \%)$ & $56(59.6 \%)$ & $20(21.3 \%)$ & .75 & \\
\hline & 3 & $14(14.7 \%)$ & $64(67.4 \%)$ & 17 (17.9\%) & .598 & \\
\hline
\end{tabular}

${ }^{a}$ Comparisons based on the number of patients with both postdose TISE images assessed and technically adequate: $n=96$ for reader $1, n=94$ for reader 2 , and $n=95$ for reader 3. Numbers in parentheses, except where noted, represent proportions of patients.

${ }^{\mathrm{b}}$ Wilcoxon signed rank test.

nificantly $(P<.0001$, all 3 readers $)$ higher postcontrast LBR values for $0.1-\mathrm{mmol} / \mathrm{kg}$ gadobenate compared with $0.1-\mathrm{mmol} / \mathrm{kg}$ gadoterate (reader 1: $1.67 \pm 0.46$ versus $1.41 \pm 0.29$; reader 2 : $1.62 \pm 0.5$ versus $1.33 \pm 0.35$; reader $3: 1.69 \pm 0.46$ versus $1.4 \pm$ 0.32 ), whereas no reader noted significant differences between $0.05-\mathrm{mmol} / \mathrm{kg}$ gadobenate and $0.1-\mathrm{mmol} / \mathrm{kg}$ gadoterate (reader $1: 1.4 \pm 0.32$ versus $1.41 \pm 0.31, P=.76$; reader $2: 1.35 \pm 0.29$ versus $1.33 \pm 0.31, P=.229$; reader $3: 1.42 \pm 0.29$ versus $1.4 \pm$ $0.29, P=.471)$.

\section{Safety}

In Arm 1 , no patients $(0 / 65 ; 0 \%)$ reported any adverse events that were considered related to $0.1-\mathrm{mmol} / \mathrm{kg}$ gadobenate, whereas 1 patient $(1 / 70 ; 1.4 \%)$ reported 1 nonserious event (headache of moderate intensity) that was considered related to $0.1-\mathrm{mmol} / \mathrm{kg}$ gadoterate. In Arm 2, two patients $(2 / 104 ; 1.9 \%)$ reported 1 adverse event each (dizziness of mild intensity, nausea of moderate intensity) that was considered related to $0.05-\mathrm{mmol} / \mathrm{kg}$ gadobenate, whereas 4 patients $(4 / 105 ; 3.8 \%)$ reported 5 adverse events (injection site swelling, injection site pruritus, dysgeusia, headache, pruritus; all of mild intensity) that were considered related to $0.1-\mathrm{mmol} / \mathrm{kg}$ gadoterate. There were no significant differences in the incidence of adverse events in either arm (Arm 1: $P=1.0000$; Arm 2: $P=.6829)$. No serious adverse events were reported.

\section{DISCUSSION}

A recent independent determination of GBCA relaxivity values in human whole blood has shown that whereas most contrast agents approved for CNS imaging have $\mathrm{r} 1$ relaxivity values between 3.9 and $4.6 \mathrm{~L} \times \mathrm{mmol}^{-1} \times$ seconds $^{-1}$ at $1.5 \mathrm{~T}$, that of gadobenate is higher at $6.2 \mathrm{~L} \times \mathrm{mmol}^{-1} \times$ seconds $^{-1.5}$. That differences in $\mathrm{r} 1$ relaxivity reflect differences in diagnostic efficacy is borne out by evidence from numerous large-scale intraindividual crossover studies. ${ }^{1-4,8-11}$ These studies have shown that differences in SI enhancement and imaging performance reflect differences in $\mathrm{r} 1$ relaxivity and that the magnitude of the differences in SI enhancement 

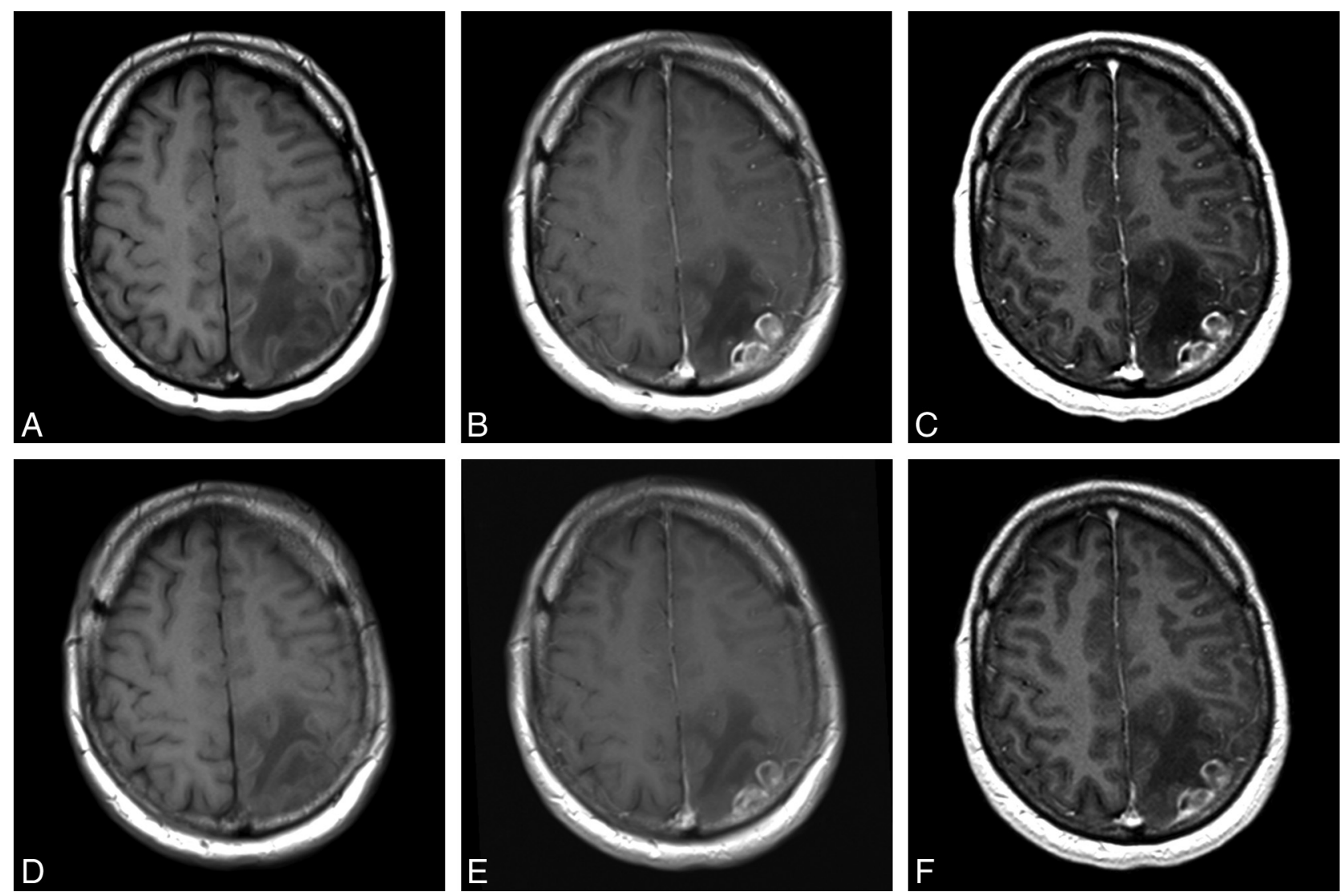

FIG 1. A 53-year-old man with left parietal glioblastoma. Images acquired before (unenhanced TISE, $A$ ) and after (TISE, B; TIGRE, C) administration of $0.1-\mathrm{mmol} / \mathrm{kg}$ gadobenate. Images acquired before (unenhanced TISE, D) and after (TISE, E; TTGRE, F) administration of 0.1-mmol/kg gadoterate. Aggressive-appearing mass with inhomogeneous enhancement shows greater lesion enhancement on images obtained with gadobenate. All blinded readers scored gadobenate images significantly higher for global preference, internal morphology, and contrast enhancement.

reflects the magnitude of the difference in $\mathrm{r} 1$ relaxivity. ${ }^{12}$ Thus, large-scale, well-controlled, prospective clinical studies have found minimal differences between GBCAs with similar $\mathrm{r} 1$ relaxivity (eg, gadopentetate dimeglumine versus gadoteridol ${ }^{8}: \mathrm{r}$, $\sim 4.2$ versus $4.4 \mathrm{~L} \times \mathrm{mmol}^{-1} \times$ seconds $^{-1}$ or gadoteridol versus gadobutrol $^{9,10}$ : r1, 4.4 versus $4.6 \mathrm{~L} \times \mathrm{mmol}^{-1} \times$ seconds $^{-1}$ ), slightly improved imaging performance for GBCAs with minimally higher $\mathrm{r} 1$ relaxivity values (eg, gadobutrol versus gadoterate ${ }^{11}$ ), and substantially improved SI enhancement and imaging performance for GBCAs with markedly higher $\mathrm{r} 1$ relaxivity (ie, gadobenate versus gadopentetate, ${ }^{1,2}$ gadobenate versus gadodiamide, ${ }^{3}$ gadobenate versus gadobutrol ${ }^{4}$ ).

Our results fully support these previous findings in confirming significantly superior imaging performance for gadobenate over gadoterate for both qualitative and quantitative enhancement when these agents are administered at equivalent approved doses of 0.1 $\mathrm{mmol} / \mathrm{kg}$ body weight. In terms of diagnostic preference, readers 1,2 , and 3 preferred gadobenate in 31 (49.2\%), 51 (82.3\%), and 43 (69.4\%) patients, respectively, compared with just 1, 2, and 2 patients for gadoterate $(P<.0001$, all readers), while highly significant $(P \leq .0023)$ superiority was noted by all readers for all other qualitative parameters.

The importance of $\mathrm{r} 1$ relaxivity is highlighted by the quantitative results of this study compared with those of other studies. Thus, Anzalone et $\mathrm{al}^{11}$ noted differences in percentage lesion enhancement and LBR of 9.9\% (97.962 versus 89.164) and 3.6\%

$$
\text { Vaneckova Sep } 2015 \text { www.ajnr.org }
$$

(1.596 versus 1.541), respectively, for gadobutrol versus gadoterate, which reflect a difference in $\mathrm{r} 1$ relaxivity of $\sim 18 \%$ based on values determined by Shen et al. ${ }^{5}$ In a comparison of gadobenate and gadobutrol, Siedl et $\mathrm{al}^{4}$ reported differences in percentage lesion enhancement and LBR of $21.8 \%-24.7 \%$ and $21.4 \%-25.0 \%$, respectively, which reflect a greater difference in $\mathrm{r} 1$ relaxivity of $\sim 35 \%$. In this study, we determined larger differences in percentage lesion enhancement and LBR of $27.6 \%-31.7 \%$ and $29.2 \%-$ $38.1 \%$, respectively, for equivalent doses of gadobenate and gadoterate, which reflect the still greater difference in $\mathrm{r} 1$ relaxivity of $\sim 59 \%$. Notably, in the study by Anzalone et al, ${ }^{11}$ the slightly greater $\mathrm{r} 1$ relaxivity of gadobutrol compared with gadoterate led to improved imaging performance for gadobutrol for some, though not all, qualitative end points, and not all blinded readers demonstrated significant preference for gadobutrol.

Whereas the findings for Arm 1 might be considered unsurprising on the basis of previous findings, ${ }^{1-4,6,13-16}$ those for Arm 2 might also have been anticipated on the basis of these same findings and those of Khouri Chalouhi et al, ${ }^{7}$ who demonstrated a markedly better signal-to-noise ratio for a three-quarter dose of gadobenate compared with a full dose of gadoterate in 31 patients who underwent cranial MR imaging examinations with both agents. In our study, all 3 blinded, expert neuroradiologists expressed no preference for either half-dose gadobenate or full-dose gadoterate in most cases. In the few cases in which a reader ex- 

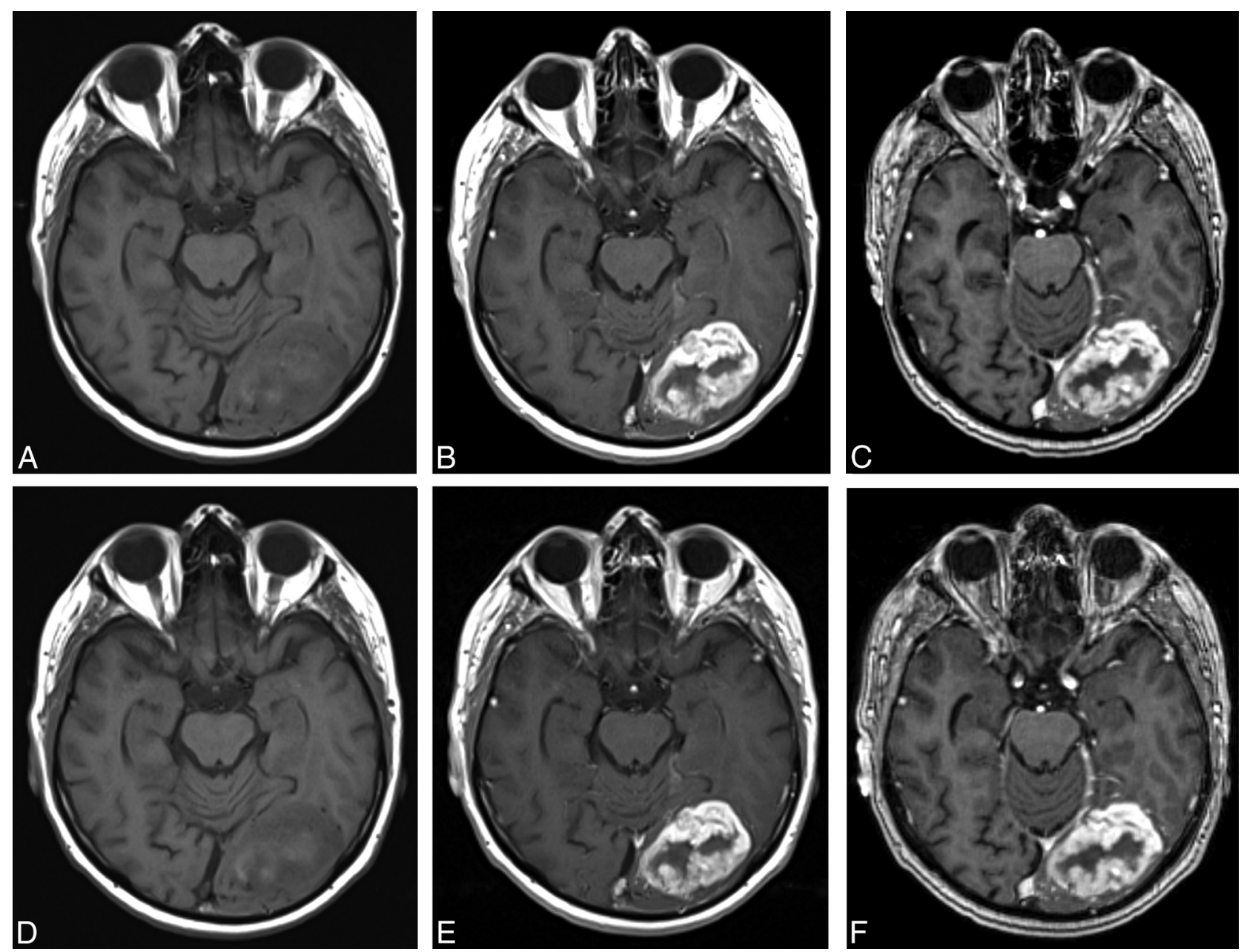

FIG 2. A 77-year-old man with a left occipital anaplastic astrocytoma. Images acquired before (unenhanced TISE, $A$ ) and after (TISE, B; TTGRE, C) administration of $0.05-\mathrm{mmol} / \mathrm{kg}$ gadobenate. Images acquired before (unenhanced TISE, D) and after (TISE, E; TTGRE, F) administration of 0.1-mmol/kg gadoterate. A single irregular ring-enhancing mass is clearly seen in both examinations; similar appearances and lesion definition and size are seen in both. All blinded readers gave similar scores for global preference, border delineation, internal morphology, and contrast enhancement, indicating equivalence for $0.05-\mathrm{mmol} / \mathrm{kg}$ gadobenate versus $0.1-\mathrm{mmol} / \mathrm{kg}$ gadoterate.

pressed preference, the number preferring $0.1-\mathrm{mmol} / \mathrm{kg}$ gadoterate was approximately equal to the number preferring $0.05-$ $\mathrm{mmol} / \mathrm{kg}$ gadobenate. Similar findings were noted for quantitative enhancement measurements: no significant differences between $0.1-\mathrm{mmol} / \mathrm{kg}$ gadoterate and $0.05-\mathrm{mmol} / \mathrm{kg}$ gadobenate were noted either for mean percentage signal enhancement (apart from reader 2 who noted higher percentage enhancement with half-dose gadobenate) or for pre- to postdose changes in LBR. The interreader agreement for assessment of images was good in all cases (complete agreement for 63.4\%-84.9\% of patients among qualitative end points). Although the interreader agreement for lesion characterization was considered only moderate $(\kappa=0.44-0.53)$, agreement was determined across 3 blinded readers rather than 2 as has been the case in some studies $^{17}$; clearly, complete agreement among 3 readers is less likely than complete agreement between 2. That the $\kappa$ values and reader agreement in Arm 2 were higher than those in Arm 1 is due to the skewed distribution of preferences in Arm 1 with readers preferring gadobenate in many more patients than gadoterate. Skewed preferences of this type are known to lower $\kappa$ values. ${ }^{18}$
In terms of clinical impact, the possibility of obtaining similar diagnostic information with a half-dose of gadobenate is potentially highly beneficial, not only in patients at risk of delayed adverse reactions such as nephrogenic systemic fibrosis and in light of recent concerns over intracranial gadolinium $(\mathrm{Gd})^{3+}$ deposition $^{19-24}$ but also in patients who require multiple GBCA doses during either a short-term period (eg, patients undergoing intraoperative MR imaging) or an extended period (eg, patients requiring regular postoperative follow-up examinations). Although not evaluated in this study, half-dose gadobenate may also be of value in patients who require long-term routine evaluation of disease evolution (eg, patients with multiple sclerosis). In this latter case, a clear understanding of the differences between GBCAs in terms of relaxivity and enhancement potential is fundamental to avoid misinterpretation of imaging findings (ie, to avoid interpretations of disease progression or therapy response, which, in reality, may be due solely to the different enhancement potential of various agents at equivalent doses).

In regard to the risk of delayed adverse reactions, whereas gadoterate has a macrocyclic structure and is widely considered a safe 

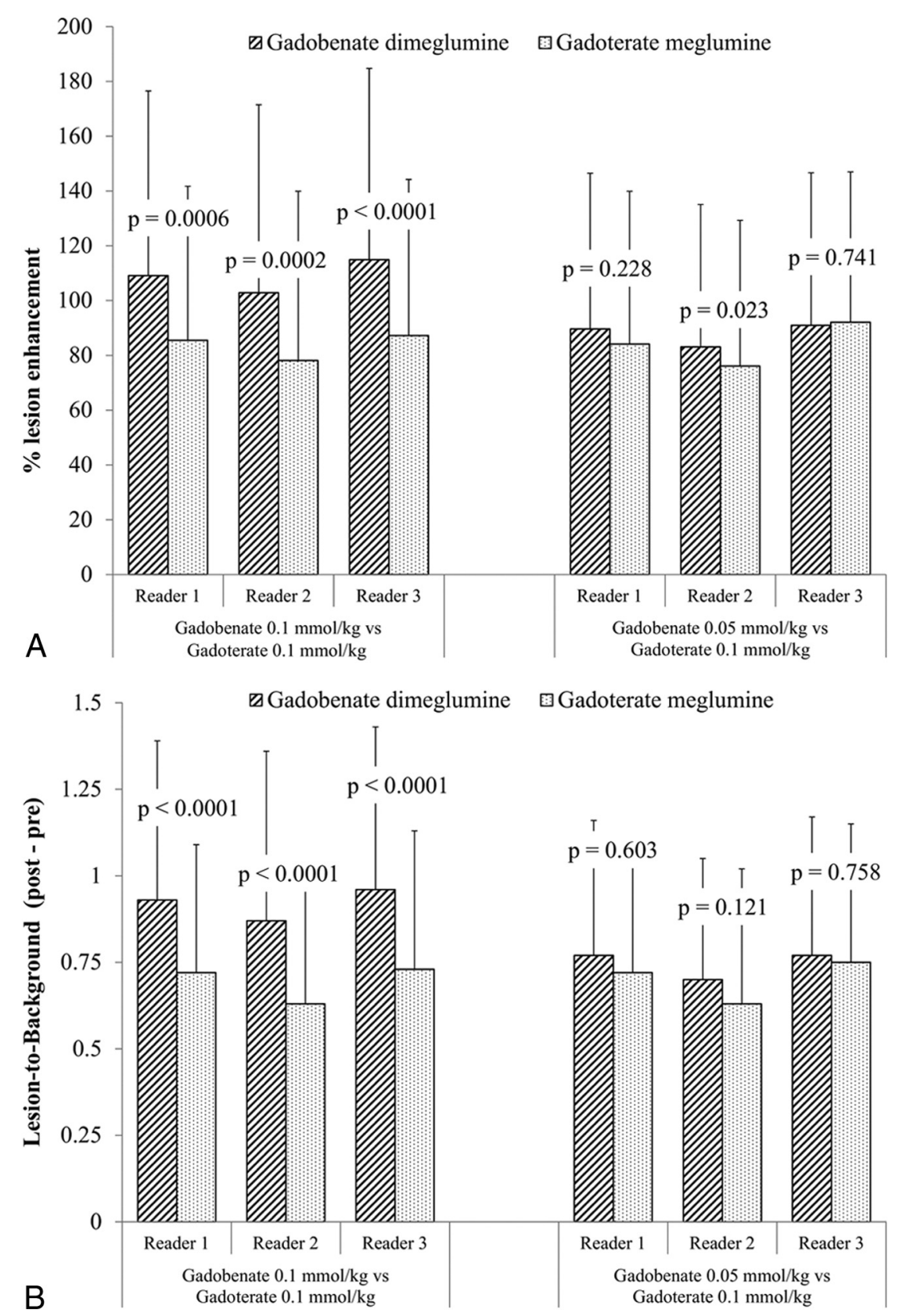

FIG 3. Blinded reader comparison of percentage lesion enhancement $(A)$ and LBR $(B)$ after administration of gadobenate and gadoterate. Highly significant increases in quantitative enhancement were noted by all readers for patients receiving $0.1-\mathrm{mmol} / \mathrm{kg}$ gadobenate compared with $0.1-\mathrm{mmol} / \mathrm{kg}$ gadoterate (Arm 1), while no differences in enhancement were noted for patients receiving $0.05-\mathrm{mmol} / \mathrm{kg}$ gadobenate compared with $0.1-\mathrm{mmol} / \mathrm{kg}$ gadoterate (Arm 2).

GBCA based on in vitro stability data, ${ }^{25}$ no cases of nephrogenic systemic fibrosis have yet been reported after the sole administration of gadobenate, ${ }^{26-28}$ and gadobenate, like gadoterate, is considered a low-risk agent for nephrogenic systemic fibrosis by the American College of Radiology and other regulatory authorities, including the US Food and Drug Administration. ${ }^{29,30}$ Moreover, unlike gadoterate, gadobenate has a dual route of elimination from the body, meaning that $\mathrm{Gd}^{3+}$ is still eliminated via the hepatobiliary pathway in even greater amounts in patients with severely impaired renal function or end-stage renal disease. ${ }^{26,27,31}$ In regard to the possibility of intracranial $\mathrm{Gd}^{3+}$ deposition, the
GBCAs most closely associated with this phenomenon as yet have been gadodiamide and gadopentetate dimeglumine (ie, the same GBCAs most frequently associated with unconfounded cases of nephrogenic systemic fibrosis). ${ }^{19-24}$ In terms of immediate-type adverse events, both gadobenate and gadoterate were safe and well-tolerated in patients with suspected or confirmed brain pathology, with no serious adverse events reported for either agent.

In common with previous studies of this type, ${ }^{1-4,8,11}$ a principal limitation is that the clinical impact of gadobenate on patient management and outcome was not directly evaluated. Although the greater diagnostic information available with full-dose gadobenate would be expected to benefit therapeutic procedures by better defining resection margins and radiosurgical target volumes, further dedicated studies are required to prove this point conclusively. A second possible limitation is that imaging was performed only at $1.5 \mathrm{~T}$. On the other hand, significant superiority for gadobenate compared with the standard relaxivity agent gadopentetate dimeglumine has also been confirmed at $3 \mathrm{~T},{ }^{2}$ while a more recent study suggests that the potential benefits of gadobenate also extend to higher field strength systems. ${ }^{32}$ Notably, in this latter study, the lesion enhancement achieved with half-dose gadobenate at $7 \mathrm{~T}$ was higher than that achieved with full-dose gadobenate at $3 \mathrm{~T}$, suggesting the possibility for dose reduction at higher field strengths. ${ }^{32}$ However, the use of half-dose gadobenate for imaging of the CNS would be considered an off-label application.

\section{CONCLUSIONS}

Two conclusions can be drawn from this study. First, gadobenate is significantly superior to gadoterate for qualitative and quantitative enhancement of brain lesions when these agents are administered at an equivalent dose of $0.1 \mathrm{mmol} / \mathrm{kg}$ body weight. Second, a half-dose of gadobenate $(0.05 \mathrm{mmol} / \mathrm{kg}$ body weight $)$ is equivalent to a full dose $(0.1 \mathrm{mmol} / \mathrm{kg}$ body weight $)$ of gadoterate and may prove advantageous when a clinical requirement is to administer a low GBCA dose. In demonstrating the value of half-dose gadobenate for brain tumor imaging, our study supports the findings of numerous previous studies across a range of MR imaging applications that have confirmed the diagnostic potential of gadobenate at $0.05 \mathrm{mmol} / \mathrm{kg}$ body weight. ${ }^{33-36}$ 
Disclosures: Manuela Vaneckova-UNRELATED: Other: Dr Vaneckova received speaker honoraria and consultant fees from Biogen Idec, Novartis, Merck Serono, and Teva, as well as support for research activities from Biogen Idec. Miroslav Herman-RELATED: Grant: Bracco Diagnostics, ${ }^{*}$ Comments: funding support for a clinical trial study. Martin P. Smith—RELATED: Grant: Bracco Diagnostics, ${ }^{*}$ Comments: research grant for recruitment and enrollment of subjects for a study; UNRELATED: Consultancy: Bayer HealthCare, Comments: consultant for contrast agent, strategic, and technical development; Grants/Grants Pending: Bayer HealthCare, ${ }^{*}$ Comments: research grant for recruitment and enrollment of subjects for a study. Kenneth R. Maravilla—RELATED: Grant: Bracco, ${ }^{*}$ Comments: clinical trial grant (payment to the University of Washington); UNRELATED: Consultancy: Guerbet; Grants/ Grants Pending: Bayer HealthCare, ${ }^{*}$ Guerbet, ${ }^{*}$ Comments: clinical trial grants for contrast media evaluation; Payment for Lectures (including service on Speakers Bureaus): ABC Medical Education; Payment for Development of Educational Presentations: ABC Medical Education. Maria Vittoria Spampinato-RELATED: Grant: Bracco, ${ }^{*}$ Comments: I was a coinvestigator in the clinical trial discussed in this article. Jan Žižka-RELATED: Other: Bracco, ${ }^{*}$ Comments: clinical trial: payments for performing MRI examinations in subjects undergoing the clinical trial MH-148. Franz J. Wippold II—RELATED: Grant: Phase IV, double-blind, multicenter, randomized, 2-arm crossover study to compare $0.1 \mathrm{mmol} / \mathrm{kg}$ of MultiHance with $0.1 \mathrm{mmol} / \mathrm{kg}$ of Dotarem in MR Imaging of the brain (BENEFIT); Principal Investigator, 2014 to present; institution received support for performing patient recruitment and scans. * Raymond Y. Huang — RELATED: Other: The cost of conducting the clinical trial at the Dana Farber Cancer Institute/Brigham and Women's Hospital site included MRI, research coordinator fee, and pharmacy costs; the members of the institutional review board were paid by the sponsor (Bracco). Jan-Hendrik Buhk-- UNRELATED: Consultancy: Codman Neurovascular (Advisory Board) Germany, Austria, and Switzerland. Miles A. Kirchin-OTHER RELATIONSHIPS: Miles A. Kirchin is an employee of Bracco Imaging S.p.A. Alain Bonafé-RELATED: Fees for Participation in Review Activities such as Data Monitoring Boards, Statistical Analysis, Endpoint Committees, and the Like: Bracco. Cesare Colosimo-UNRELATED: Consultancy: Bayer Pharma, Bracco Diagnostics. Gianpaolo Pirovano-OTHER RELATIONSHIPS: employee of Bracco Diagnostics. Ningyan Shen-OTHER RELATIONSHIPS: employee of Bracco Diagnostics. Alberto Spinazzi-OTHER RELATIONSHIPS: Alberto Spinazzi, MD, is an employee of Bracco Diagnostics, the company that sponsored the clinical trial that is the subject of this publication. Su Lui-RELATED: Support for Travel to Meetings for the Study or Other Purposes: Bracco Diagnostics, Comments: As one of the blind readers, the company covered my traveling fee from China to Italy to join the study; Fees for Participation in Review Activities such as Data Monitoring Boards, Statistical Analysis, Endpoint Committees, and the Like: Bracco Diagnostics, Comments: Bracco Diagnostics paid me for reading the images for the MH-148 study. *Money paid to the institution.

\section{REFERENCES}

1. Maravilla KR, Maldjian JA, Schmalfuss IM, et al. Contrast enhancement of central nervous system lesions: multicenter intraindividual crossover comparative study of two MR contrast agents. $\mathrm{Ra}$ diology 2006;240:389-400 CrossRef Medline

2. Rumboldt Z, Rowley HA, Steinberg F, et al. Multicenter, doubleblind, randomized, intra-individual crossover comparison of gadobenate dimeglumine and gadopentetate dimeglumine in MRI of brain tumors at 3 Tesla. J Magn Reson Imaging 2009;29:760-67 CrossRef Medline

3. Rowley HA, Scialfa G, Gao PY, et al. Contrast-enhanced MR imaging of brain lesions: a large-scale intraindividual crossover comparison of gadobenate dimeglumine versus gadodiamide. AJNR Am J Neuroradiol 2008;29:1684-91 CrossRef Medline

4. Seidl Z, Vymazal J, Mechl M, et al. Does higher gadolinium concentration play a role in the morphologic assessment of brain tumors? Results of a multicenter intraindividual crossover comparison of gadobutrol versus gadobenate dimeglumine (the MERIT Study). AJNR Am J Neuroradiol 2012;33:1050-58 CrossRef Medline

5. Shen Y, Goerner FL, Snyder C, et al. T1 relaxivities of gadoliniumbased magnetic resonance contrast agents in human whole blood at 1.5, 3, and 7 T. Invest Radiol 2015;50:330-38 CrossRef Medline

6. Colosimo C, Knopp MV, Barreau X, et al. A comparison of GdBOPTA and Gd-DOTA for contrast-enhanced MRI of intracranial tumours. Neuroradiology 2004;46:655-65 CrossRef Medline

7. Khouri Chalouhi K, Papini GD, Bandirali M, et al. Less is better? Intraindividual and interindividual comparison between $\mathbf{0 . 0 7 5}$ $\mathrm{mmol} / \mathrm{kg}$ of gadobenate dimeglumine and $0.1 \mathrm{mmol} / \mathrm{kg}$ of gadoter- ate meglumine for cranial MRI. Eur J Radiol 2014;83:1245-49 CrossRef Medline

8. Greco A, Parker JR, Ratcliffe CG, et al. Phase III, randomized, double-blind, cross-over comparison of gadoteridol and gadopentetate dimeglumine in magnetic resonance imaging of patients with intracranial lesions. Australas Radiol 2001;45:457-63 CrossRef Medline

9. Maravilla KR, Smith MP, Vymazal J, et al. Are there differences between macrocyclic gadolinium contrast agents for brain tumor imaging? Results of a multicenter intraindividual crossover comparison of gadobutrol with gadoteridol (the TRUTH study). AJNR Am J Neuroradiol 2015;36:14-23 CrossRef Medline

10. Gutierrez JE, Rosenberg M, Seemann J, et al. Safety and efficacy of gadobutrol for contrast-enhanced magnetic resonance imaging of the central nervous system: results from a multicenter, doubleblind, randomized, comparator study. Magn Reson Insights 2015;8: 1-10 CrossRef Medline

11. Anzalone N, Scarabino T, Venturi C, et al. Cerebral neoplastic enhancing lesions: multicenter, randomized, crossover intraindividual comparison between gadobutrol (1.0M) and gadoterate meglumine $(0.5 \mathrm{M})$ at $0.1 \mathrm{mmol} \mathrm{Gd} / \mathrm{kg}$ body weight in a clinical setting. Eur J Radiol 2013;82:139-45 CrossRef Medline

12. Kanal E, Maravilla K, Rowley HA. Gadolinium contrast agents for CNS imaging: current concepts and clinical evidence. AJNR Am J Neuroradiol 2014;35:2215-26 CrossRef Medline

13. Colosimo C, Ruscalleda J, Korves M, et al. Detection of intracranial metastases: a multicenter, intrapatient comparison of gadobenate dimeglumine-enhanced MRI with routinely used contrast agents at equal dosage. Invest Radiol 2001;36:72-81 CrossRef Medline

14. Knopp MV, Runge VM, Essig M, et al. Primary and secondary brain tumors at MR imaging: bicentric intraindividual crossover comparison of gadobenate dimeglumine and gadopentetate dimeglumine. Radiology 2004;230:55-64 CrossRef Medline

15. Essig M, Tartaro A, Tartaglione T, et al. Enhancing lesions of the brain: intraindividual crossover comparison of contrast enhancement after gadobenate dimeglumine versus established gadolinium comparators. Acad Radiol 2006;13:744-51 CrossRef Medline

16. Kuhn MJ, Picozzi P, Maldjian JA, et al. Evaluation of intraaxial enhancing brain tumors on magnetic resonance imaging: intraindividual crossover comparison of gadobenate dimeglumine and gadopentetate dimeglumine for visualization and assessment, and implications for surgical intervention. J Neurosurg 2007;106:557-66 CrossRef Medline

17. Koenig M, Schulte-Altedorneburg G, Piontek M, et al. Intra-individual, randomised comparison of the MRI contrast agents gadobutrol versus gadoteridol in patients with primary and secondary brain tumours, evaluated in a blinded read. Eur Radiol 2013;23:3287-95 CrossRef Medline

18. Feinstein AR, Cicchetti DV. High agreement but low kappa, I: the problems of two paradoxes. J Clin Epidemiol 1990;43:543-49 CrossRef Medline

19. Kanda T, Ishii K, Kawaguchi $\mathrm{H}$, et al. High signal intensity in the dentate nucleus and globus pallidus on unenhanced T1weighted MR images: relationship with increasing cumulative dose of a gadolinium-based contrast material. Radiology 2014;270: 834-41 CrossRef Medline

20. Errante Y, Cirimele V, Mallio CA, et al. Progressive increase of T1 signal intensity of the dentate nucleus on unenhanced magnetic resonance images is associated with cumulative doses of intravenously administered gadodiamide in patients with normal renal function, suggesting dechelation. Invest Radiol 2014;49:685-90 CrossRef Medline

21. Kanda $\mathrm{T}$, Osawa $\mathrm{M}$, Oba $\mathrm{H}$, et al. High signal intensity in dentate nucleus on unenhanced T1-weighted MR images: association with linear versus macrocyclic gadolinium chelate administration. $R a-$ diology 2015;275:803-09 CrossRef Medline

22. McDonald RJ, McDonald JS, Kallmes DF, et al. Intracranial gadolin- 
ium deposition after contrast-enhanced MR imaging. Radiology 2015;275:772-82 CrossRef Medline

23. Quattrocchi CC, Mallio CA, Errante Y, et al. Gadodiamide and dentate nucleus $\mathrm{T} 1$ hyperintensity in patients with meningioma evaluated by multiple follow-up contrast-enhanced magnetic resonance examinations with no systemic interval therapy. Invest Radiol 2015; 50:470-72 CrossRef Medline

24. Radbruch A, Weberling LD, Kieslich PJ, et al. Gadolinium retention in the dentate nucleus and globus pallidus is dependent on the class of contrast agent. Radiology 2015;275:783-91 CrossRef Medline

25. Idée JM, Port $M$, Robic $C$, et al. Role of thermodynamic and kinetic parameters in gadolinium chelate stability. J Magn Reson Imaging 2009;30:1249-58 CrossRef Medline

26. Heverhagen JT, Krombach GA, Gizewski E. Application of extracellular gadolinium-based MRI contrast agents and the risk of nephrogenic systemic fibrosis. Rofo 2014;186:661-69 CrossRef Medline

27. Soulez G, Bloomgarden DC, Rofsky NM, et al. Nephrogenic systemic fibrosis in patients with stages 3 to 5 chronic kidney disease undergoing MRI with the injection of gadobenate dimeglumine or gadoteridol: findings from prospective cohort studies. $A J R A m J$ Roentgenol. In press

28. Nandwana SB, Moreno CC, Osipow MT, et al. Gadobenate dimeglumine administration and nephrogenic systemic fibrosis: is there a real risk in patients with impaired renal function? Radiology 2015 Apr 15. [Epub ahead of print] CrossRef Medline

29. American College of Radiology (ACR) Manual on Contrast Media. Version 9. 2013. http://www.acr.org/quality-safety/resources/ /media/ 37D84428BF1D4E1B9A3A2918DA9E27A3.pdf/. Accessed June 19, 2015

30. The Royal Australian and New Zealand College of Radiologists. Guideline on the Use of Gadolinium-Containing MRI Contrast Agents in
Patients with Renal Impairment. https://www.nephrology.edu.au /members/documents/GuidelinesontheUseofGadolinium-containing MRIContrastAgents10thSeptember.pdf. Accessed June 19, 2015

31. Kirchin MA, Lorusso V, Pirovano G. Compensatory biliary and urinary excretion of gadobenate ion after administration of gadobenate dimeglumine (MultiHance $\left.{ }^{\circledR}\right)$ ) in cases of impaired hepatic or renal function: a mechanism that may aid in the prevention of nephrogenic systemic fibrosis? Br J Radiol 2015;88: 20140526 CrossRef Medline

32. Noebauer-Huhmann IM, Szomolanyi P, Kronnerwetter C, et al. Brain tumours at 7T MRI compared to 3T-contrast effect after half and full standard contrast agent dose: initial results. Eur Radiol 2015;25:106-12 CrossRef Medline

33. Sandstede JJ, Beer M, Lipke C, et al. Time course of contrast enhancement patterns after Gd-BOPTA in correlation to myocardial infarction and viability: a feasibility study. J Magn Reson Imaging 2001;14:789-94 CrossRef Medline

34. Achenbach M, Figiel JH, Burbelko M, et al. Prospective comparison of image quality and diagnostic accuracy of 0.5 molar gadobenate dimeglumine and 1.0 molar gadobutrol in contrast-enhanced runoff magnetic resonance angiography of the lower extremities. $J$ Magn Reson Imaging 2010;32:1166-71 CrossRef Medline

35. Morana G, Grazioli L, Kirchin MA, et al. Solid hypervascular liver lesions: accurate identification of true benign lesions on enhanced dynamic and hepatobiliary phase magnetic resonance imaging after gadobenate dimeglumine administration. Invest Radiol 2011;46: 225-39 CrossRef Medline

36. Schneider G, Probst T, Kirchin MA, et al. Low-dose gadobenate dimeglumine-enhanced MRI of the kidney for the differential diagnosis of localized renal lesions. Radiol Med 2015 Jun 19. [Epub ahead of print] CrossRef Medline 